\title{
The relationship between attendance and academic performance of undergraduate medical students during surgical clerkship
}

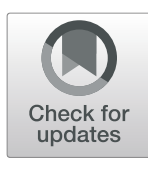

Hamdi Al Shenawi ${ }^{1 *}$, Rami Yaghan ${ }^{1,2}$, Amer Almarabheh $^{3}$ and Noor Al Shenawi ${ }^{4}$

\begin{abstract}
Background: The current study aimed to evaluate the previously unexplored correlation between undergraduate medical students' attendance during their surgical clerkship and their academic performance. It also aimed to explore any difference in the attendance rate between male and female students and whether this difference, if present, affects the academic performance.

Methods: A retrospective descriptive cross-sectional study has been conducted on 331 undergraduate medical students during their surgical clerkships at the College of Medicine and Medical Sciences (CMMS) at Arabian Gulf University (AGU), Bahrain from September 2018 to June 2020.

Results: There was a positive statistically significant correlation between students' attendance during surgical clerkship and academic performance $(r=0.360, P<0.01)$. Mean attendance rate was greater in each increasing category of academic performance: $47.95 \%$ in the weak category (less than $65 \%, n=42$ ), $57.62 \%$ in the good performance category ( $65 \%$ to less than $75 \%, n=108), 67.82 \%$ in the very good performance category ( $75 \%$ to less than $85 \%, n=126), 83.16 \%$ in the excellent performance category ( $85 \%$ and above, $n=55)$. The mean attendance rate of male students was $59.76 \%(S D=25.73)$, compared to $66.92 \%(S D=24.30)$ in the female students. T-test indicated that the difference between the mean attendance of the two groups of the students (male, female) was statistically significant $(t=2.483, p<0.05)$. On the other hand, the difference between the mean academic performance for the two groups of students, male \& female, $(t=0.284, p=0.777)$ was not statistically significant.

Conclusions: Our study showed a significant relationship between undergraduate medical students' attendance during their surgical clerkship and their academic performance. Further studies are needed to stratify this correlation according to clinical and theoretical teaching activities. No significant difference was observed in academic performance between female and male students.
\end{abstract}

Keywords: Attendance 1, Achievement 2, Performance 3, Correlation 4, Surgical clerkship 5, Gender 6

\footnotetext{
* Correspondence: hamdims@agu.edu.bh

'Department of SurgeryCollege of Medicine and Medical Sciences, Arabian Gulf University, Manama, Bahrain

Full list of author information is available at the end of the article
} 


\section{Background}

The vast majority of medical literature is indicative of a clear synergistic correlation between medical student attendance, and academic achievement [1-15]. The key for an undergraduate medical student to fulfil academic achievements and rewards is to attend the learning activities and be fully committed. This positive correlation has been observed at all student levels including those with low scoring abilities [1]. Despite this global realization, absenteeism of undergraduate students from medical and health science schools continues to be a major issue negatively affecting student performance [1]. Class participation helps to enhance the student's understanding of the topics discussed, aids in facilitating class activities, and allows the student to develop ethical and moral values. In addition, attendance is an essential part of providing regulatory perspectives for sound professionalism [2, 16]. Absenteeism entails negative impacts on institutions as well. The university resources are underused, the teaching staff are not motivated, and the student-teacher relationship becomes burdensome [3].

Academic authorities have proposed several causes for academic absenteeism. The most common causes were pop quizzes, long break periods between classes, and the performance of some teachers who resort to just reading the text provided on the slides [3]. Another common cause for absenteeism is having 'prior- years printed handouts' prepared by senior students. This theory agrees with some European research that assigned a large percentage of student absences to resources that allow students to access all notes and study material without attending classes [3]. New technologies have aided the increase of absenteeism by allowing more access to information at home. One of the limitations of the arguments for and against obligatory class attendance focuses only on the students' academic performance and not on the principles and experience a student acquires from the classroom. One study proved that students who attend $40 \%$ of the classes practice human values to a higher degree compared to students attending less than $40 \%$ of the classes [16].

The above-mentioned correlation between attendance and performance outcome [4], was not specifically studied in undergraduate surgical clerkship programs. Surgical rotations have their own merits. We believe that in medical education, particularly in clinical surgical training, regular attendance of the students enhances the competence and confidence level of the students. In addition, regular attendance helps in increasing student's exposure to hot and cold surgical cases and having increased opportunities to practice basic surgical procedures. Also, attendance allows the students to understand responsibilities and work dynamics as a member of a surgical team. This study aimed to explore the extent of correlation between attendance and performance among undergraduate medical students during their surgical clerkship in particular. It also aimed to explore any difference in the attendance rate between male and female students and whether this difference, if present, affects the academic performance.

\section{Methods}

\section{Type of study}

A retrospective descriptive cross-sectional study.

\section{Study target and population}

Final year medical students (year six) during their 17-week surgical clerkship for two consecutive full academic years (2018/2019 \& 2019/2020). The rotation included general surgery, pediatric surgery, vascular surgery, plastic surgery, urology, orthopedic surgery, anesthesiology, and accident and emergency services.

\section{Data collection and study instrument}

The required data has been collected from the computer database at the department of surgery, and the assessment office at CMMS at AGU, Bahrain. The study period extended from September 2018 to June 2020.

There were 4 surgical clerkship rotations with a total number of 331 students. Students were expected to attend 124 activities per rotation (44 afternoon problembased activities, 5 professional skills at Simulation Center, and 75 hospital-based clinical activities).

This 17-week surgical clerkship introduces students to the basic principles of general surgery and surgical subspecialties. It is designed to equip the undergraduate students with the fundamental knowledge, basic skills, and attitudes relevant to a sound surgical practice.

The clinical surgical rotation program has taken place at AGU campus, Salmaniya Medical Complex, and King Hamad University Hospital. These are the largest two governmental teaching hospitals affiliated to CMMSAGU. Student attendance of all clinical and tutorialbased activities was confirmed using a paper-based logbook. The logbook was checked and signed by the assigned tutor on daily basis. Student attendance was defined as full attendance of the hospital-based activities, simulation center activities, and the problem-based activities at AGU campus. By mid-March 2020, our institution implemented precautionary measurements against COVID-19 dissemination. In this regard, students were not allowed to attend in hospitals. Compensatory teaching activities were immediately introduced using zoom application. These included a variety of small group interactive clinically-oriented activities including case studies, seminars, and video simulations. Attendance of students was assured by making the video-on option compulsory. A dedicated secretary 
recorded the details of attendance of each student by the continuous monitoring of the screen in each activity. It is worth mentioning here that the training in our institution officially ends by late April during the academic year. May and June will be the examination preparation period, and the examination periods for the clinical clerkships and the general MD graduation exams. This meant that by the time COVID-19 closure has started, the concerned batch of students have already fulfilled two thirds of their regular clinical training.

\section{Exposures}

The attendance rate (as a total percentage) for each student was calculated as a function of the actual number of activities attended to the total number of scheduled activities. All activities were given an equal weight.

The academic performance of each student at the end of each surgical clinical rotation at CMMS-AGU is calculated according to the following percentages: clerkship continuous assessment (25\%), short answer questions (10\%), multiple choice questions (25\%), objective structured clinical examination, (10\%) and clinical encounter examination (30\%).

The $25 \%$ of clerkship continuous assessment has been excluded from calculation because it depends largely on attendance. By this, we have eliminated the potential bias that might affect our statistical evaluation of the correlation between attendance and academic performance. This also reduces the subjectivity of the tutors' own perception. The remaining $75 \%$ of the academic performance has been converted to $100 \%$ in our calculation.

\section{Statistical analysis}

The Data has been entered in MS Excel and analyzed using Statistical Package for the Social Sciences (SPSS Version 27). Study Variables: The dependent variable is academic performance (scores), and the independent variables are attendance and gender. Variables have been presented as counts and percentages or as means and standard deviations where applicable. Two independent samples t-tests were used to test the significant mean differences in student performance in surgical clerkship rotation scores regarding the percentage of attendance and gender.

The Pearson correlation coefficient was used to measure the linear relationship between the surgical clerkship rotation score and the percentage of attendance. A scatter diagram and a simple regression line were used to present the association between two previously quantitative variables. Chi-square test was used to measure the association between students' attendance and student's performance in clerkship rotation, and gender. Additionally, the chi-square test was used to measure the association between students' performance in clerkship rotation, and attendance. A p-value of less than 0.05 was considered statistically significant.

\section{Results}

A total of (331) final year medical students (Table 1) completed the 17- week surgical rotation during the study period. Out of these, 111 (33.5\%) were males, and $220(66.5 \%)$ were females. The mean attendance rate of surgical clerkship rotation \pm SD was $64.53 \% \pm 24.98 \%$, and the mean of overall academic performance \pm SD was $75.12 \% \pm 11.33 \%$.

\section{Relationship between attendance rates and academic performance}

The results of Pearson correlation coefficient are shown in (Fig. 1). There was a positive statistically significant correlation between surgical clerkship attendance, and academic performance $(\mathrm{r}=0.360, P<0.01)$.

\section{Attendance rate according to performance levels}

Mean attendance rate was greater in each increasing category of academic performance: $47.95 \%$ in the weak category (less than 65, n=42), 57.62\% in the good performance category ( $65 \%$ to less than $75 \%, n=108$ ), $67.82 \%$ in the very good performance category $(75 \%$ to less than $85 \%, n=126$ ), and $83.16 \%$ in the excellent performance category ( $85 \%$ and above, $n=55$ ) (Fig. 2).

\section{Academic performance according to attendance categories}

The mean student performance was greater in each increasing category of attendance: $69.97 \%(\mathrm{SD}=12.16 \%$, $n=102)$ in the $50 \%$ or lower category, $73.10 \%$ (SD $=$ $7.91 \%, n=22$ ) in the 50 to $59 \%$ category, $74.33 \%$ (SD = $7.32 \%, n=31)$ in the 60 to $69 \%$ category, $76.69 \%(\mathrm{SD}=$ $7.27 \%, n=56)$ in the 70 to $79 \%$ category, $78.83 \%$ (SD = $8.71 \%, n=65)$ in the 80 to $89 \%$ category, and $79.67 \%$ $(\mathrm{SD}=14.67 \%, n=55)$ in the 90 to $100 \%$ category (Fig. 3).

\section{Gender-based attendance rate and academic performance score}

The mean attendance rate of male students \pm SD was $59.76 \% \pm 25.73 \%$, compared to $66.92 \% \pm 24.30 \%$ in the female students, (Table 2). The results of $\mathrm{t}$-test indicated that this difference was statistically significant $(t=2.483$,

Table 1 Total number of the targeted students

\begin{tabular}{llllll}
\hline Gender & \multicolumn{5}{l}{ Four Surgical Clerkship Rotations - Year $\mathbf{6}$} \\
\cline { 2 - 6 } & $\mathbf{R 1}$ & $\mathbf{R 2}$ & $\mathbf{R 3}$ & $\mathbf{R 4}$ & Total \\
\hline Male & 31 & 32 & 23 & 25 & 111 \\
Female & 53 & 58 & 53 & 56 & 220 \\
Total & 84 & 90 & 76 & 81 & 331 \\
\hline
\end{tabular}




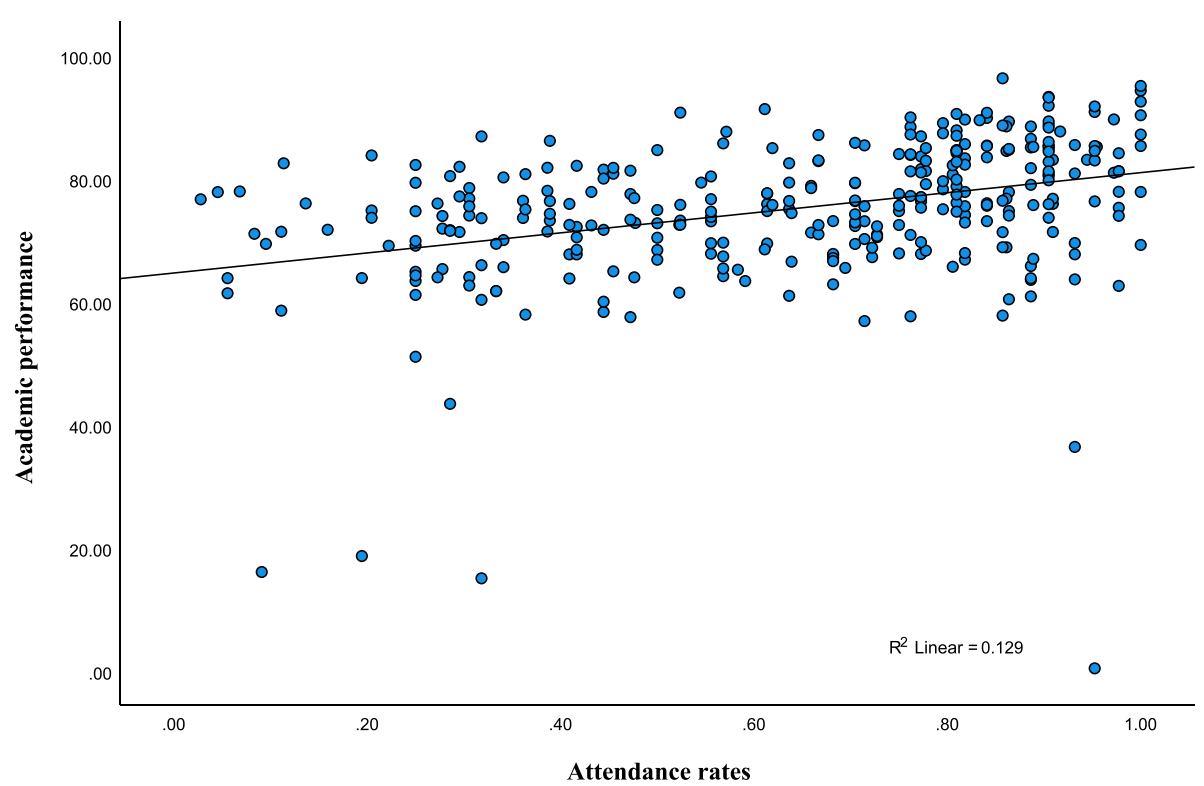

Fig. 1 Scatter plot of the positive linear correlation betwwen attendance and performance

$p<0.05)$. On the other hand, the difference between the mean of academic performance for the two groups (male, female) students $(\mathrm{t}=0.284, p=0.777$ ) was not statistically significant.

\section{Factors associated with attendance rates}

According to the attendance rate, students were divided into two categories; those who attended $\leq 50 \%$, and those who attended $>50 \%$. According to the student's performance, the students were divided into four categories: excellent $(\geq 85)$, very good (75 to $<85)$, good ( 65 to $<$ $75)$, and weak $(<65)$. Chi-square tests (Table 3$)$ showed that there was a significant association between attendance category and academic performance level ( $p$-value $<0.001)$. On the other hand, the association between attendance category and gender was not statistically significant ( $\mathrm{p}$-value $>0.05$ ).

Previous performance might be a potential confounding variable associating better performance to an underlying characteristic of the learner, rather the attendance rate. We have compared the scores of the high performing group in surgery in the current study $(n=55)$, to their previous scores in internal medicine during their fifth year using the paired sample t-test. The mean in

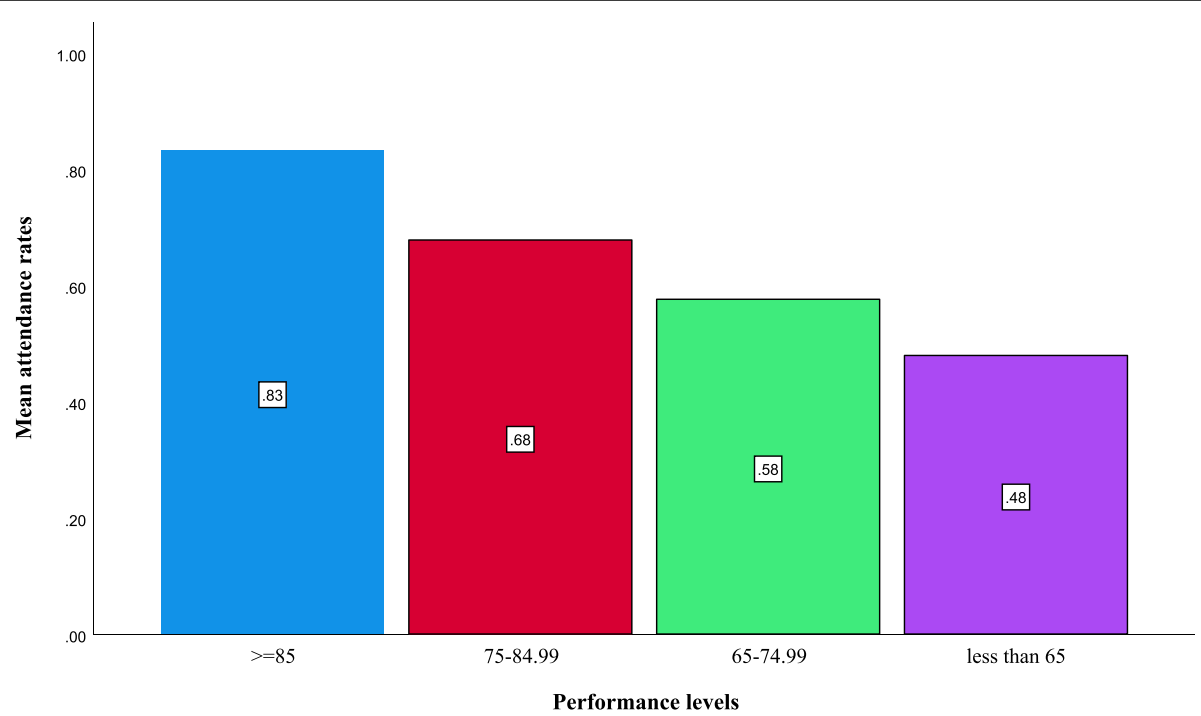

Fig. 2 The mean of attendace rate according to the academic performance levels 


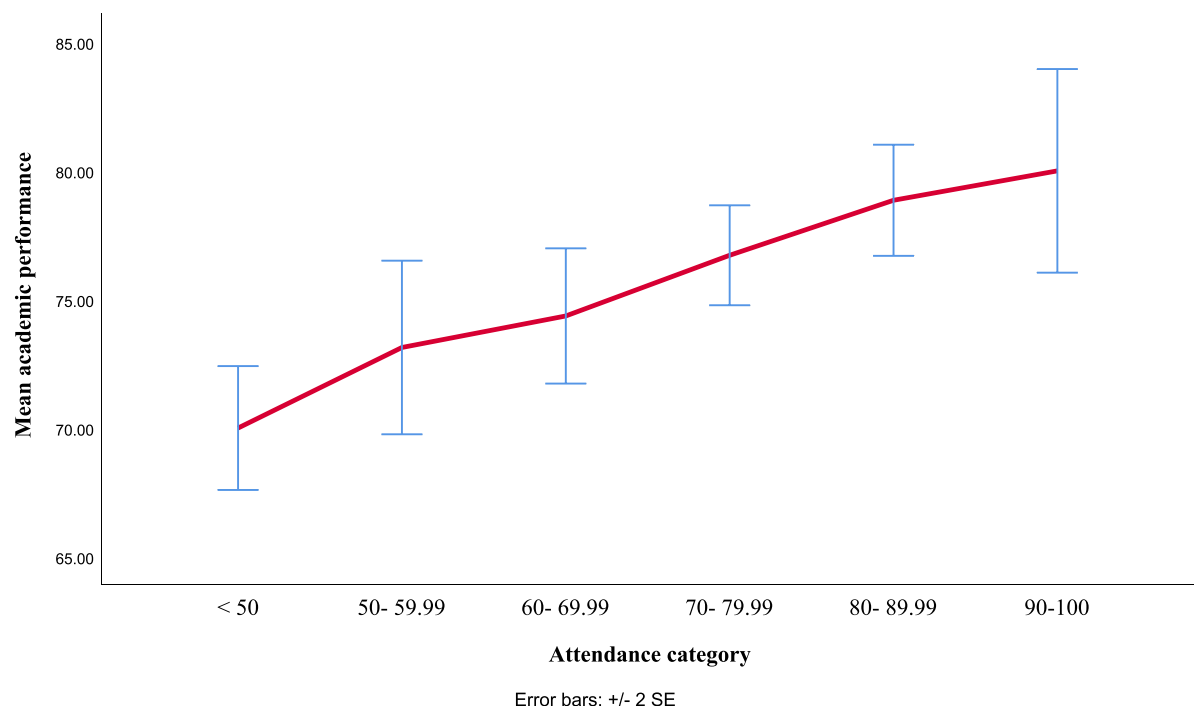

Fig. 3 The mean of academic perforamnce score according attendance rate category

the surgery clerkship was $(88.42, \mathrm{SD}=2.82)$, compared to $(80.92, \mathrm{SD}=6.82)$ in the internal medicine. The paired sample t-test indicated that this difference was statistically significant. (Mean Diff. $=-7.497,95 \%$ C. $I=-9.205$ to $-5.789, p<0.001)$. Out of the 55 students falling in the high-performance category in the current study, only $32.72 \%$ achieved a similar high-performance score-range in internal medicine.

\section{Discussion}

The preponderance of evidence indicates a clear positive correlation between medical student attendance in general, and the learning outcome achievement and student scoring (Table 4). However, there is no previous data regarding such a correlation during the surgical clinical clerkship in particular.

We believe that the undergraduate surgical clinical training has some inherent properties that differentiate it from other disciplines and intensify the necessity of student physical attendance in the clinical hospital-based and classroom-based learning activities. Most patients with cold surgical problems and specific physical signs would visit the hospital for a short period only once or twice before having their definitive curative surgery. This will naturally reduce the student chances to see surgical cold cases, calling for a more dedicated physical student attendance. The nature of the cold cases in surgery also reduces the chance of creating a comprehensive standardized patient (SP) program. A patient with a hernia, for example, will be advised to have his hernia repaired as soon as possible. This is different from a patient with mild or moderate aortic incompetence who can be enrolled in a controlled SP program for timely student training.

Also, surgical training includes a wide range of clinical skills (like wound follow-up, simple catheter insertions and removals, and the multidisciplinary operating theatre approach), which can only be monitored by direct face-to-face and, occasionally, supervised hands-on practicing. On the other hand, emergency surgical cases will most of the time be operated upon within a short period, limiting the student's chances to witness the real initial clinical presentation.

Exposure of medical students to real cold and emergency surgical cases gives them a good chance to learn how to assess these cases properly, make quick logical decisions, build their communication skills, obtain consent from patients, and train on breaking bad news.

Table 2 Gender-based attendance rates and academic performance score

\begin{tabular}{|c|c|c|c|c|}
\hline \multirow[t]{2}{*}{ Variable } & Male $(n=111)$ & Female $(n=220)$ & \multirow{2}{*}{$\begin{array}{l}\text { T. } \\
\text { value }\end{array}$} & \multirow{2}{*}{$\begin{array}{l}P \\
\text { value }\end{array}$} \\
\hline & Mean \pm SD & Mean \pm SD & & \\
\hline Attendance rate (\%) & $59.76 \pm 25.73$ & $66.92 \pm 24.30$ & 2.483 & $0.014^{*}$ \\
\hline Academic Performance & $75.37 \pm 12.28$ & $74.99 \pm 10.85$ & 0.284 & 0.777 \\
\hline
\end{tabular}


Table 3 The association between academic performance, gender, and attendance rate category

\begin{tabular}{|c|c|c|c|c|c|c|c|}
\hline \multirow[t]{2}{*}{ Variable } & \multirow{2}{*}{$\begin{array}{l}\text { Performance } \\
\text { Level }\end{array}$} & \multicolumn{2}{|c|}{ Attendance $\leq \mathbf{5 0 \%}$} & \multicolumn{2}{|c|}{ Attendance $>50 \%$} & \multirow[t]{2}{*}{ Total } & \multirow{2}{*}{$\begin{array}{l}P \\
\text { value }\end{array}$} \\
\hline & & $\bar{n}$ & $\%$ & $\bar{n}$ & $\%$ & & \\
\hline \multirow[t]{5}{*}{ Academic Performance $^{a}$} & Excellent & 9 & 5.3 & 46 & 28.4 & 55 & $<0.001$ \\
\hline & Very Good & 54 & 32.0 & 72 & 44.4 & 126 & \\
\hline & Good & 74 & 43.8 & 34 & 21.0 & 108 & \\
\hline & Weak & 32 & 18.9 & 10 & 6.2 & 42 & \\
\hline & Total & 169 & 100 & 162 & 100 & 331 & \\
\hline \multirow[t]{3}{*}{ Gender } & Male & 65 & 38.5 & 46 & 28.4 & 111 & 0.052 \\
\hline & Female & 104 & 61.5 & 116 & 71.6 & 220 & \\
\hline & Total & 169 & 100 & 162 & 100 & 331 & \\
\hline
\end{tabular}

${ }^{a}$ : Excellent $(\geq 85)$, Very good $(75$ to $<85)$, Good $(65$ to $<75)$, Weak $(<65)$

The specific surgical training features alluded to above, prompted us to investigate the correlation between attendance and performance during the surgical training as a separate discipline.

Our study revealed a significant positive correlation between undergraduate medical students' attendance and academic performance during their surgical clerkship (Tables 2,3). These findings are consistent with most of previous reports assessing the correlation between attendance and academic performance but in other disciplines [1-22] (Table 4). However, Kauffman CA et al. and Yeager L et al. found no correlation between attendance and academic performance [23, 24].

We believe that the undergraduate medical students in their clinical surgical rotations should be strictly followed with a close attendance monitoring system for a better outcome. In our institution, a logbook is used by each student and is signed daily by the assigned responsible tutor after the student physically fulfills the requested task. In our institution, the continuous student assessment is also partially dependent on the ratio of attendance. More studies are needed to explore further the specific advantages of strict adherence to attendance during the clinical surgical rotations.

Among our study group, there was no significant difference in academic performance between female and male students during the undergraduate surgical clerkship (Table 2). However, female students had a higher attendance rate compared to male students. Similarly, in this regard, Al Khaja KA et al., Fadelelmoula $\mathrm{T}$ et al., Ayodele OD et al., and Faisal R et al. recorded no significant correlation between gender and academic performance in other disciplines [5, 17, 18, 25] (Table 4). However, other studies reported that female students imply a better academic performance compared to male students [7, 12, 13, 26, 27] (Table 4).
Further research is required to have a better understanding of the relationship between gender and academic performance in undergraduate medical students during the clinical surgical clerkship. Previous learner performance is a recognized predictor of future success for learners. If most of our study subjects, falling in the high performing group, had previous high academic performance, then it could equally be stated that high performing students were more likely to have high attendance rates. In other words, previous performance might be a potential confounding variable associating better performance to an underlying characteristic of the learner, rather than merely the attendance rate. To address this more deeply, we have compared. The scores of the high performing group in surgery in the current study, to their previous scores in internal medicine during their fifth year. The mean score in the surgery clerkship was (88.42), compared to (80.92) in the internal medicine clerkship. This difference was statistically significant. (Mean Diff. $=-7.497,95 \%$ C. $\mathrm{I}=-9.205$ to -5.789 , $p<0.001)$. This favors the conclusion that, within our study group, the attendance rate was the main predictor of better performance compared to previous scores in other disciplines.

\section{Limitations}

Our study included a relatively small number of students calling for further studies.

Among our study group, performance results were not segregated according to clinical hospital-based and theoretical classroom-based activities, creating another issue for future studies.

\section{Conclusion}

In consistency with other medical disciplines, there was a positive correlation between undergraduate student 
Table 4 A summary of representative publications evaluating the relationship between student's attendance, gender, and academic performance

\begin{tabular}{|c|c|c|}
\hline $\begin{array}{l}\text { Author, } \\
\text { year of publication }\end{array}$ & $\begin{array}{l}\text { Relationship between attendance } \\
\text { \& academic performance }\end{array}$ & $\begin{array}{l}\text { The difference in academic performance } \\
\& \text { attendance according to gender }\end{array}$ \\
\hline $\begin{array}{l}\text { Current study } \\
\text { Al Shenawi et al. }\end{array}$ & + (positive correlation) & $\begin{array}{l}\text { No significant effect but Females have more } \\
\text { attendance than males }\end{array}$ \\
\hline Khan YL et al., 2019 [1] & + (positive correlation) & Not applicable \\
\hline Thatcher A et al., 2007 [2] & + (positive correlation) & Not applicable \\
\hline Landin M et al., 2015 [3] & + (positive correlation) & Not applicable \\
\hline Deane RP et al., 2013 [4] & + (positive correlation) & Not applicable \\
\hline Al Khaja KA et al., 2019 [5] & + (weak correlation) & No significant effect \\
\hline Subramaniam BS et al., 2013 [6] & + (positive correlation) & Not applicable \\
\hline Daud S et al., 2012 [7] & + (positive correlation) & $\begin{array}{l}\text { Female students have better attendance rate } \\
\& \text { academic performance than male }\end{array}$ \\
\hline Dhaliwal UP et al., 2003 [8] & + (positive correlation) & Not applicable \\
\hline Khan HU et al., 2003 [9] & + (positive correlation) & Not applicable \\
\hline BinSaeed AA et al., 2009 [10] & + (positive correlation) & Not applicable \\
\hline Sharmin T et al., 2016 [11] & + (positive correlation) & Not applicable \\
\hline Sharma S et al., 2019 [12] & + (strong correlation) & Academic performance of female students better than males \\
\hline Roy SS et al., 2014 [13] & + (weak correlation) & Academic performance of female students better than males \\
\hline Nowreen N et al., 2019 [14] & + (positive correlation) & Not applicable \\
\hline Silva ET et al., 2010 [15] & + (positive correlation) & Not applicable \\
\hline Cheruvalath R et al., 2017 [16] & + (positive correlation) & Not applicable \\
\hline Fadelelmoula T et al., 2018 [17] & + (positive correlation) & No significant effect \\
\hline Ayodele OD et al., 2017 [18] & + (positive correlation) & No significant effect \\
\hline Marburger DR et al., 2006 [19] & + (positive correlation) & Not applicable \\
\hline Schnee D et al., 2019 [20] & + (positive correlation) & Not applicable \\
\hline Lukkarinen A et al., 2016 [21] & + (positive correlation) & Not applicable \\
\hline Aldamen H et al., 2015 [22] & + (positive correlation) & Not applicable \\
\hline Kauffman CA et al., 2018 [23] & No correlation & Not applicable \\
\hline Yeager L et al., 2018 [24] & No correlation & Not applicable \\
\hline Faisal R et al., 2017 [25] & Not applicable & No significant effect \\
\hline Albalawi M et al., 2019 [26] & Not applicable & Academic performance of female students better than males \\
\hline Cortright RN et al., 2011 [27] & Not applicable & $\begin{array}{l}\text { Attendance on academic performance is more significant } \\
\text { for female students than males. }\end{array}$ \\
\hline
\end{tabular}

attendance during the surgical clerkship and academic performance. No significant difference was observed in academic performance between female and male students. Further studies are needed to segregate the relationship between student's attendance, gender, and academic performance according to clinical and theoretical teaching activities.

\section{Abbreviations}

CMMS: College of Medicine and Medical Sciences; AGU: Arabian Gulf University; SD: Standard deviation; SP: Standardized patient; R1: surgical rotation 1; R2: surgical rotation 2; R3: surgical rotation 3; R4: surgical rotation 4

\section{Supplementary Information}

The online version contains supplementary material available at https://doi. org/10.1186/s12909-021-02833-2.

Additional file 1. "Article title, Author, and affiliations".

Additional file 2. "Result of Surgery Exams -R1, R2, R3, R4" Data not shown.

\section{Acknowledgements}

The authors would like to acknowledge Dr. Fuad Abdulla (Chair of Assessment Unit at CMMS -AGU) for facilitating data collection. 


\section{Authors' contributions}

HA and RY conceived and designed the study; HA performed the research process and collected the data; AA performed the statistical analyses; HA and RY wrote the original draft of the manuscript; HA, AA and NA prepared the figures and tables; HA, RY, AA and NA edited and revised the manuscript; RY was the project manager; $\mathrm{HA}, \mathrm{RY}, \mathrm{AA}$ and $\mathrm{NA}$ approved the final version of the manuscript.

\section{Funding}

This research received no external funding.

\section{Availability of data and materials}

All data generated or analysed during this study are included in this published article [and its supplementary information file -Results of Surgery Exams R1, R2, R3, R4].

\section{Declarations}

\section{Ethics approval}

This research was approved by Ethical committee of CMMS-AGU, Bahrain. (Reference number: E006-PI-9/20).

All methods were performed in accordance with the relevant guidelines and regulations.

Consent for participation, our research was approved by Ethical committee of CMMS-AGU which include exemption from consent as it was not applicable.

\section{Consent for publication}

All authors have read the manuscript and agreed to all its contents. All authors gave their consent for publication.

\section{Competing interests}

The authors declare that they have no competing interests.

\section{Author details}

'Department of SurgeryCollege of Medicine and Medical Sciences, Arabian Gulf University, Manama, Bahrain. ${ }^{2}$ Department of Surgery and Urology, Faculty of Medicine, Jordan University of Science and Technology, Irbid, Jordan. ${ }^{3}$ Department of Family and Community Medicine, College of Medicine and Medical Sciences, Arabian Gulf University, Manama, Bahrain. ${ }^{4}$ Undergraduate medical student, College of Medicine and Medical Sciences, Arabian Gulf University, Manama, Bahrain.

Received: 13 November 2020 Accepted: 13 July 2021

Published online: 22 July 2021

\section{References}

1. Khan YL, Lodhi SK, Bhatti S, Ali W. Does Absenteeism Affect Academic Performance Among Undergraduate Medical Students? Evidence From "Rashid Latif Medical College (RLMC).". Adv Med Educ Pract. 2019;10:999 Online available on: https://www.ncbi.nlm.nih.gov/pmc/articles/ PMC6897060/ [DOI] [Google Scholar] [PubMed].

2. Thatcher A, Fridjhon P, Cockcroft K. The relationship between lecture attendance and academic performance in an undergraduate psychology class. South Afr J Psychol. 2007;37(3):656-60 Online available on: https:// journals.sagepub.com/doi/abs/10.1177/008124630703700316 [DOI] [Google Scholar].

3. Landin M, Pérez J. Class attendance and academic achievement of pharmacy students in a European University. Curr Pharmacy Teach Learn. 2015;7(1):78-83 Online available on: https://www.sciencedirect.com/science/ article/abs/pii/S1877129714001361 [DOI] [Google Scholar].

4. Deane RP, Murphy DJ. Student attendance and academic performance in undergraduate obstetrics/gynecology clinical rotations. Jama. 2013;310(21): 2282-8 Online available on: https://jamanetwork.com/journals/jama/articleabstract/1787409 [DOI] [Google Scholar] [PubMed].

5. Al Khaja KA, Tayem Y, James H, Jaradat A, Sequeira RP. Pharmacology and therapeutics resource session attendance and academic performance of pre-clerkship medical students in problem-based learning curricula. BMC Med Educ. 2019;19(1):269 Online available on: https://bmcmededuc. biomedcentral.com/articles/10.1186/s12909-019-1699-3 [DOI] [Google Scholar] [PubMed].
6. Subramaniam BS, Hande S, Komattil R. Attendance and achievement in medicine: Investigating the impact of attendance policies on academic performance of medical students. Ann Med Health Sci Res. 2013;3(2):202 Online available on: https://www.ncbi.nlm.nih.gov/pmc/articles/ PMC3728863/ [DOI] [Google Scholar] [PubMed].

7. Daud S, Javaid FA. Effect of class attendance of medical students' tests performance. Pak J Med Health Sci. 2012;6(2):295-7 [Google Scholar].

8. Dhaliwal UP. Absenteeism and under-achievement in final year medical students. Nat Med J India. 2003;16(1):34-6 Online available on: https://www. researchgate.net/profile/Upreet_Dhaliwal2/publication/10786518_ Absenteeism_and_under achievement_in_final_year_medical_students/ links/552e1af30cf21acb09219b6c/Absenteeism-and-under-achievement-infinal-year-medical-students.pdf [Google Scholar] [PubMed].

9. Khan HU, Khattak AM, Mahsud IU, Munir A, Ali S, Khan MH, et al. Impact of class attendance upon examination results of students in basic medical sciences. J Ayub Med Col Abbottabad. 2003;15(2) Online available on: https://pubmed.ncbi.nlm.nih.gov/14552252/ [Google Scholar] [PubMed].

10. BinSaeed AA, Al-Otaibi MS, Al-Ziyadi HG, Babsail AA, Shaik SA. Association between student absenteeism at a medical college and their academic grades. J Int Assoc Med Sci Educ. 2009;19(4):155-9 Online available on: http://www.iamse.org/mse-article/association-between-studentabsenteeism-at-a-medical-college-and-their-academic-grades/ [Google Scholar].

11. Sharmin T, Azim E, Choudhury S, Kamrun S. Reasons of absenteeism among undergraduate medical students: a review. Anwer Khan Modern Med Col J. 2017;8(1):60-6 Online available on: https://www.banglajol.info/index.php/ AKMMCJ/article/view/31660 [DOI] [Google Scholar].

12. Sharma S, Biswas S, Chakraborty S. Does Mandatory Attendance and Residence Affect Academic and Gender based Performance in 1st Year Undergraduate MBBS Students? Online available on: https://d1wqtxts1xzle7. cloudfront.net/53419259/ijcmr_1075_dec_10.pdf?1496830941=\&responsecontent-disposition=inline\%3B+filename\%3DDoes_Mandatory_Attendance_ and_Residence.pdf\&Expires=1605039208\&Signature=hKfqwekelantLxA XcUwq9aa2x9Ay5sqAtzNgP5nZyMH5rAZJ2Ej4c6Y0nQYly45dPpyW qyjCjPB9nnbi5fmcY6zEgpN3PUz5GKvjPBncmklkMRRx1-SDfoLu3VRJHbThEt YEIK-R8nCnodj9k709K5BhFkgDS-szhrLfFr1NdEdlAbs

vbmq1 rbdaxnZGcm9ZfEb-3TyKfzn3MRzRgxTihcXz4gISxGii4-472m7o3h2otl UwJ2kSzjYPRVor3tRdteKTqly2L5FkwCIF5xEyFhSDUbi6zTQJ-iz-qkF bwjdxHpceTAJ D7urDQNjZ3MFzNFFPOwJVg-RdsThvMw_\&Key-Pair-ld= APKAJLOHF5GGSLRBV4ZA [Google Scholar].

13. Roy SS, Chadalawada J. Predictors of academic performance of medical undergraduate students of microbiology class in Kolkata. Int J Med Public Health. 2014;4(4) Online available on: https://ijmedph.org/article/319 [Google Scholar].

14. Nowreen N, Chowdhary S, Hameed R. Impact of class attendance on academic performance in the subject of physiology. Nat J Physiol Pharm Pharmacol. 2019;9(6):524-6 Online available on: http://www.njppp.com/ index.php?mno=38189 [Google Scholar].

15. Silva ET, Nunes MD, Queiroz MG, Leles CR. Factors influencing students' performance in a Brazilian dental school. Brazilian Dental J. 2010;21(1):80-6 Online available on: https://www.scielo.br/scielo.php?pid=S010364402010000100013\&script=sci_abstract\&tlng=es [Google Scholar] [PubMed].

16. Cheruvalath R. Does attending classes help foster human values in college students? Active Learn Higher Educ. 2017;18(2):143-55 Online available on: https://journals.sagepub.com/doi/abs/10.1177/1469787417707616 [DOI] [Google Scholar].

17. Fadelelmoula T. The impact of class attendance on student performance. Int Res J Med Med Sci. 2018;6(2):47-9 Online available on: http://www. netjournals.org/pdf/IRJMMS/2018/2/18-021.pdf [DOI] [Google Scholar].

18. Ayodele OD. Class attendance and academic performance of second year university students in an organic chemistry course. Afr J Chem Educ. 2017; 7(1):63-75 Online available on: https://www.ajol.info/index.php/ajce/article/ view/151090 [Google Scholar].

19. Marburger DR. Does mandatory attendance improve student performance? J Econ Educ. 2006;37(2):148-55 Online available on: https://www. tandfonline.com/doi/abs/10.3200/JECE.37.2.148-155 [DOI] [Google Scholar].

20. Schnee D, Ward T, Philips E, Torkos S, Mullakary J, Tataronis G, et al. Effect of Live Attendance and Video Capture Viewing on Student Examination Performance. Am J Pharmaceutical Educ. 2019;83(6) Online available on: https://www.ajpe.org/content/83/6/6897.abstract [Google Scholar] [PubMed]. 
21. Lukkarinen A, Koivukangas P, Seppälä T. Relationship between class attendance and student performance. Procedia Soc Behav Sci. 2016;228(16): 341-7 Online available on: https://acris.aalto.fi/ws/portalfiles/portal/ 11716697/1_s2.0_S1877042816309776_main.pdf [Google Scholar].

22. Aldamen $\mathrm{H}$, Al-Esmail R, Hollindale J. Does lecture capturing impact student performance and attendance in an introductory accounting course? Accounting Educ. 2015;24(4):291-317 Online available on: https://www. tandfonline.com/doi/abs/10.1080/09639284.2015.1043563 [Google Scholar].

23. Kauffman CA, Derazin M, Asmar A, Kibble JD. Relationship between classroom attendance and examination performance in a second-year medical pathophysiology class. Adv Physiol Educ. 2018:42(4):593-8 Online available on: https://journals.physiology.org/doi/full/10.1152/advan.00123. 2018 [DOI] [Google Scholar].

24. Yeager L, Valenzuela S, Marino M, Carney PA. an observational study of the impact of attendance on preclinical undergraduate medical education performance. Educ Res Appl. 2018; Online available on: https:// gavinpublishers.com/articles/research-article/Educational-ResearchApplications-ISSN-2575-7032/an-observational-study-of-the-impact-ofattendance-on-preclinical-undergraduate-medical-education-performance [Google Scholar].

25. Faisal R, Shinwari L, Hussain SS. Academic performance of male in comparison with female undergraduate medical students in Pharmacology examinations. JPMA. 2017;67(204) Online available on: https://mail.jpma.org. pk/PdfDownload/8078 [Google Scholar] [PubMed].

26. Albalawi M. Does gender difference have an effect in the academic achievements of undergraduate students' and later as interns? A single medical college experience, Taibah University, KSA. Allied J Med Res. 2019; 3(1):20-25. 22 Allied J Med Res 2019 Volume 3 Issue.;1:4. [Google Scholar].

27. Cortright RN, Lujan HL, Cox JH, DiCarlo SE. Does sex (female versus male) influence the impact of class attendance on examination performance? Adv Physiol Educ. 2011;35(4):416-20 Online available on: https://journals. physiology.org/doi/full/10.1152/advan.00021.2011 [Google Scholar] [PubMed].

\section{Publisher's Note}

Springer Nature remains neutral with regard to jurisdictional claims in published maps and institutional affiliations.

Ready to submit your research? Choose BMC and benefit from:

- fast, convenient online submission

- thorough peer review by experienced researchers in your field

- rapid publication on acceptance

- support for research data, including large and complex data types

- gold Open Access which fosters wider collaboration and increased citations

- maximum visibility for your research: over $100 \mathrm{M}$ website views per year

At $\mathrm{BMC}$, research is always in progress.

Learn more biomedcentral.com/submissions 